\title{
The Effects of Fin Parameters on the Solidification of PCMs in a Fin-Enhanced Thermal Energy Storage System
}

\author{
Mohammad Javad Zarei ${ }^{1}$, Hassan Bazai ${ }^{2}{ }^{\oplus}$, Mohsen Sharifpur ${ }^{2}{ }^{\oplus}$, Omid Mahian $^{3,4}$ and \\ Bahman Shabani ${ }^{5, *}$ \\ 1 Faculty of Advanced Technologies, NanoChemical Engineering Department, Shiraz University, \\ Shiraz 71345, Iran; saeeed.zarei.69@gmail.com \\ 2 Department of Mechanical and Aeronautical Engineering, University of Pretoria, Private Bag X20, \\ Hatfield 0028, Pretoria, South Africa; bazaee.hassan@gmail.com (H.B.); mohsen.sharifpur@up.ac.za (M.S.) \\ 3 School of Chemical Engineering and Technology, Xi'an Jiaotong University, Xi'an, Shaanxi 710049, China; \\ omid.mahian@gmail.com \\ 4 Department of Mechanical Engineering, Quchan University of Technology, Quchan 94771, Iran \\ 5 Mechanical and Automotive Engineering, School of Engineering, RMIT University, Bundoora 3083, Australia \\ * Correspondence: bahman.shabani@rmit.edu.au
}

Received: 4 December 2019; Accepted: 26 December 2019; Published: 1 January 2020

\begin{abstract}
In the present study, a triplex-tube, employing fin-enhanced phase change materials (PCMs), as a thermal energy storage (TES) system was studied numerically. The main flaw of the PCMs is their low thermal conductivity that restricts their effectiveness for energy storage applications. Metallic (copper) fins are added to the geometry of the system to improve their function by extending the heat transfer area. The effects of the presence, configuration, and dimensions of copper fins were investigated to understand the best design for minimizing the solidification time and achieving the best performance enhancement for the TES system selected for this study. The results revealed that the best performance belonged to fins with a mix configuration, with an attachment angle of $90^{\circ}$ and the length and width of $28 \mathrm{~mm}$ and $1 \mathrm{~mm}$, respectively. Using this configuration could reduce the required time for complete solidification by around $42 \%$ compared to the system without fins. Moreover, it was concluded that increasing the length of the fin could offer its positive effect for enhancing the performance of TES system up to an optimal point only while increasing the width showed a diverse influence. Furthermore, the angles between the tube surface and the fin direction were investigated and $90^{\circ}$ was found to be the best choice for the TES case selected in this study. In addition, placement of the fins on the surface of internal or external tube or mix method did not show a significant effect while placing the fins on the external surface of the tube showed even a negative impact on the performance of the TES system compared with when no fins were applied.
\end{abstract}

Keywords: thermal energy storage; numerical modeling; phase change materials; solidification; fins

\section{Introduction}

The solar energy provides an alternative source of energy to replace fossil fuels for generating heat $[1,2]$. However, its main challenge is the intermittency of solar radiation. Hence, by focusing on solar thermal systems, thermal energy storage (TES) solutions are seen as an integrated part of such systems to ensure the continuity of supply. Generally, TESs are divided into latent heat thermal energy storage (LHTES), sensible heat storage (SHS), and thermochemical energy storage [3-6]. LHTES systems work with phase change materials (PCMs) [7-9] and involve an almost isothermal 
charging/discharging process. They have several merits including high-energy storage density, being a mature technology, and working in a wide temperature range.

The solid-liquid PCMs that can easily change to liquid and solid phases are classified into three types of inorganic, organic, and eutectic PCMs. They possess different ranges of transformation temperatures used in both low-temperature and high-temperature solar energy storage systems for different purposes including solar cooking, air and water heating, solar power plants, and drying process by solar energy [10-13].

One of the most important weaknesses of PCMs is their low thermal conductivity that affects their function in energy storage devices in terms of rate of thermal charging and discharging. As extensively studied before [14-22], application of extended surfaces such as fins is one of the methods that can address this problem. The thermal conductivity of metal fins is far higher than PCMs that help increase the heat transfer rate between the heat transfer fluid (HTF) and the PCM. This results in enhancing the overall performance of the LHTES systems in terms of rate of thermal charging and discharging [10]. Applying fins is also an economical option due to being easy to fabricate [6]. Different key characteristics of these fins such as thermal conductivity, geometry and configuration, material (e.g., being corrosion resistance), and cost must be considered when designing them for performance enhancement of PCMs. [8].

Employing fins as a helpful method for enhancement of heat transfer rate during melting and solidification processes (i.e., to improve the TES function) was investigated numerically by several researchers. Henze and Humphrey [23] investigated the melting behavior of a PCM by proposing and validating it 2D model in a thermal energy storage device in which fins with equal spaces were used. Their model could predict the average fraction of the melted PCM with an acceptable precision. Besides, Lacroix [24] developed a mathematical model using the enthalpy method to simulate the transient phase change process inside a shell and tube TES system in the presence of external fins. They found that the fins with annular geometry were very effective for enhancing the heat transfer stored during the phase change process up to $63 \%$ in the presence of 19 fins and $44 \%$ for the case with 12 fins. Velraj et al. [25] studied the phase change process of the PCM of paraffin RT60 in a vertical circular tube that was internally finned as the TES system located in an external tube containing HTF of water. They reported that using a V-shaped fin configuration was the most effective way to maximize the performance of the PCM-based energy storage systems they studied.

Afterwards, Gharebaghi and Sezai [26] used a numerical model to study a finned heat sink that worked with RT27 as PCM in vertical and horizontal orientations. They proved that in the case studies with a significant temperature difference $\left(20^{\circ} \mathrm{C}\right.$ in their study), addition of the fins played a significant role to augment the heat transfer rate up to 80 times for different case studies compared to the system without fins. Moreover, they demonstrated that the reduction in spaces between the fins could accelerate the melting process up to $50 \%$, i.e., the parameter that was considered equal and constant in Henze and Humphrey [23] study.

Moreover, Sciacovelli et al. [27] conducted a numerical study to analyze the influence of using Y-shaped fins on the thermal discharging process of a thermal energy storage system. It was concluded that Y-shaped fins with wide angles of branches were more efficient for short operating times, whereas Y-shaped fins with smaller angles were more stable during longer-term operation of the thermal storage system.

It is important to indicate that all of the above-mentioned studies were focused only on investigating the geometry and configurations of the fins.

Darzi et al. [28] then numerically investigated the hybrid effects of nanoparticles and radial conductive fins on the melting and solidification enhancement of PCMs inside a cylindrical annulus. They illustrated that the presence of fins was more effective than introducing nanoparticles for improving the heat transfer rates of the PCM during both melting and solidification processes. The improvement obtained by fins were $28 \%, 62 \%, 75 \%$, and $85 \%$ by using $4,10,15$, and 20 fins, respectively, while the enhancement by nanoparticles addition were $9 \%$ and $16 \%$ using $2 \%$ and $4 \%$ of nanoparticles. However, 
it was revealed that this enhancement was more beneficial during the solidification process compared to that in the melting process. Similarly, Al-Abidi et al. [29] examined the effect of introducing metallic fins on the enhancement of solidification of the PCM while nanoparticles were used simultaneously. The length of the fins was considered as a variable and its effect was investigated to determine the best achievable performance of the TES system. The results indicated that increasing the length of the fins could enhance the function of the TES as the required time to complete solidification could be reduced up to $35 \%$. In that study, the number of fins and their dimensions were analyzed and optimized to acquire the best performance for the TES unit. Furthermore, Mahdi and Nsofor [17,30] investigated the solidification and melting process of a PCM inside a triplex-tube thermal energy storage system in the presence of fins and nanoparticles. They concluded that the required time for both solidification and melting decreased by addition of both fins and nanoparticles. However, similar to the findings of Darzi et al. [28], they showed that using fins without introducing nanoparticles resulted in the best performance. They also simulated this thermal storage system to survey the influence of the fins with different novel configurations (i.e., attached to the internal tube) on the energy storage function while simple longitudinal fins were linked to the external tube. They showed that the configuration of fins can have a significant impact on the level of performance enhancement of the TES they studies [31].

In another study, Alizadeh et al. [32] proposed a numerical model to simulate the phase change process of the $\mathrm{PCM}$ and the influences of introducing hybrid nanoparticles of $\mathrm{TiO}_{2}-\mathrm{Cu}$ and addition of Y-shaped fins on the performance of the latent heat thermal energy storage system they used in their study. They noticed that both geometry modification (bifurcation angle and fin length increase) and nanoparticles shape factor can augment the transient phase change process. Moreover, they noticed that the presence of the fins was much more effective compared to nanoparticles, i.e., endorsing the results obtained by Mahdi and Nsofor [17,30] and Darzi et al. [28].

Previous numerical studies were mostly dedicated to studying or optimizing just one of the effective parameters of the fins among configuration, dimensions, type, contact angle, junction of fins and geometry. Moreover, although various studies were conducted on TES systems, there are different effective parameters that they have not investigated yet that can particularly improve their efficiency significantly. In most of these studies, the presence of fins with only a specific geometry was investigated. However, all of these fin parameters are interlarded suggesting that fin design and optimization for performance enhancement of PCMs must done by considering the effect of all key involving parameters simultaneously.

In response to this gap in the literature, in the present research, the details of a numerical model are provided to determine the influence of key fins design parameters (i.e., to be integrated in a PCM chamber) on the performance improvement of PCMs. RT82 as the PCM was selected for this study placed inside a triplex-tube thermal energy storage system. Despite other studies that investigated some limited fin features, in the present study the effects of the presence of the fin, the placement of the fins on the external tube, internal tube, and a mixed case study (on both internal and external tubes). The angles between the fins direction and the tangent line to the tube surfaces $\left(45^{\circ}\right.$ and $90^{\circ}$ ), and fins dimensions (length and width of the fins with rectangular cross section) were studied and compared to the TES system without fins. To obtain the best fin design to be employed in the TES system selected for this study. The outcomes of this comprehensive numerical study will be used as a user guide for utilizing TES systems equipped with metallic fins. As mentioned earlier, the fins material is an important parameter that significantly influences the rate of heat transfer in TES systems. Considering the manufacturing costs as well as durability and thermal conductivity of different materials, we selected copper as the fin material to be used in this study.

Following the introduction, Section 2 of this paper details the modeling procedure used in this study including an overview of the modeling approach, geometry of the computational domain, fins and PCM details, assumptions and governing equations, and mesh independency and accuracy of the numerical model. Then in Section 3, the results of the Computational fluid dynamics (CFD) simulation 
are detailed and compared for different case studies. Moreover, in this section the results are provided and discussed in details. Finally, the paper is concluded in Section 4.

\section{Modeling Procedure}

\subsection{Overview of the Modeling Approach}

In this study, the solidification of a PCM inside a triplex-tube thermal energy storage system was modeled numerically in order to investigate the effects of copper fin properties introduced to enhance the solidification rate of the PCM selected for this study. The key properties investigated include dimensions, configuration and the order of attachment, and the contact angle of the fins. For numerical modeling of the phase change process of the PCM (solidification), governing equations of momentum and heat distribution for liquid PCM were the Navier-Stokes and energy equations. These equations should be discretized and solved numerically for the whole domain. A CFD simulation was applied to model the transient behavior of the phase change process. The thermo-physical properties of the PCM and fins, the accurate and well-meshed geometries and the methods of discretization of the governing equations are of great importance as inputs to the CFD simulation. Moreover, both temperature and liquid fraction of the computational domain were recorded as outputs of the numerical modeling in order to compare different case studies. Besides, the time that is required for complete solidification of the PCM was the key parameter to be understood for designing an efficient PCM-based TES system.

\subsection{Triplex-Tube Details}

In this study, the triplex-tube of experimental study of Al-Abidi [33] was modeled as the energy storage system. Figure 1 is a schematic view of the cross section of the triplex-tube with rectangular copper fins as a horizontal longitudinally-finned triplex-tube heat exchanger. The triplex-tube was made by three $500 \mathrm{~mm}$ long concentric copper tubes with three different diameters of 50.8, 150 and $200 \mathrm{~mm}$ in a row. The internal tube had a thickness of $1.2 \mathrm{~mm}$ while the middle and external tubes had a $2 \mathrm{~mm}$ thickness. The PCM utilized in this research was RT82 due to its suitability for being used in phase-change processes without super-cooling and stable performance in multiple thermal cycling [17]. PCM filled the empty space between internal and middle tubes. Water as the heat transfer fluid circulated within internal and the space between the middle and external tubes. Eight copper longitudinal fins with similar length $(L)$ and width $(w)$ were attached to the external surface of the internal tube as well as the internal side of the middle tube (i.e., Figure 1). Four fins were placed on the middle tube as two fins were vertical, and two others were horizontal. Other fins were linked to the internal tube with a $45^{\circ}$ horizontal angle. Fin length and width were changed to analyze the effect of dimension for proposing the most effective design/arrangement. 


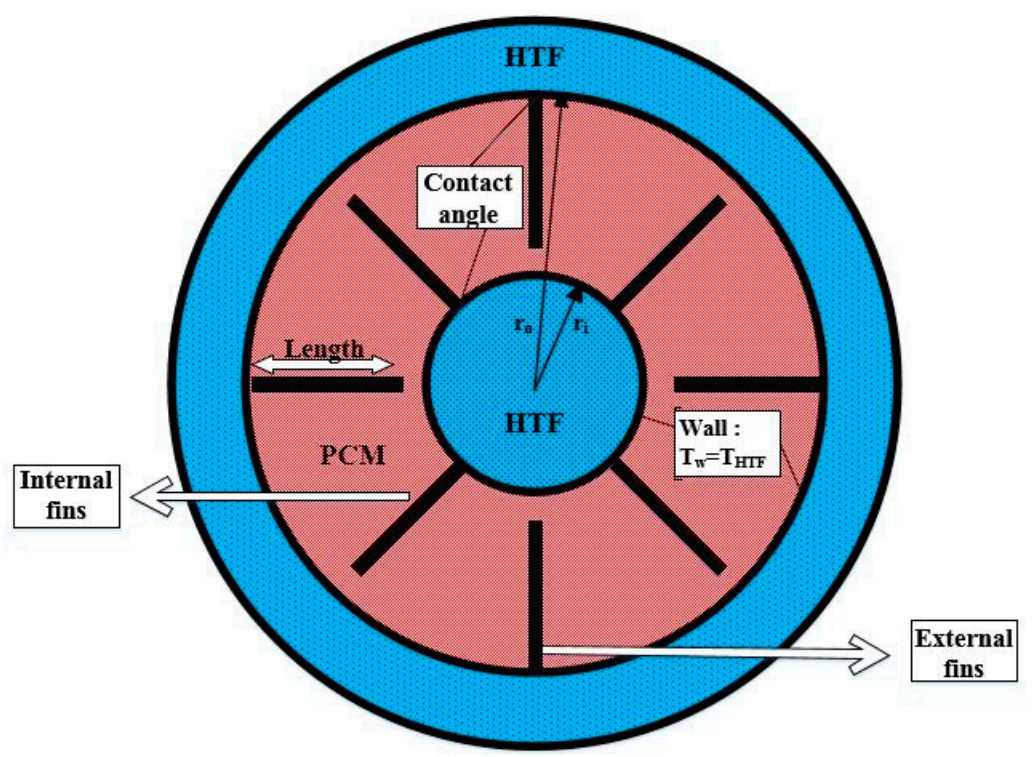

Figure 1. A 2D schematic of the triplex-tube showing the fins' parameters and configuration (internal fins are those attached to the inner tube while external fins were linked to the outer tube).

\subsection{Assumptions and Governing Conditions}

As in Mahdi and Nsofor study [17], the computational domain was finned in longitudinal direction and filled with the PCM between $r_{o}$ and $r_{i}$, the radius of the middle and inner tubes in a row. It was assumed that the PCM and fins had the constant temperature of $366 \mathrm{~K}$ (liquid phase) at the beginning of the solidification process. Therefore, the initial condition was $\mathrm{T}=366 \mathrm{~K}$.

The surfaces of the middle area (red color in Figure 1) were exposed to the HTF with lower temperature than the solidus temperature $\left(T_{S}\right)$ of the PCM $\left(343 \mathrm{~K}, T_{W}<T_{S}\right)$. The boundary conditions were defined as:

$\begin{aligned} \text { i. } & r & =r_{i}, T=T_{w}=366 \mathrm{~K} \\ \text { ii. } & r & =r_{0}, T=T_{w}=366 \mathrm{~K}\end{aligned}$

To start the solidification process, heat transfer between the surfaces and PCM is required. The driving force for this heat transfer is the temperature difference between $T_{w}$ and $T_{S}\left(T_{W}<T_{S}\right)$.

In the solid PCM without any phase change, the heat transfer during the solidification is the result of conduction while in the liquid PCM area both conduction and some degrees of convection play role in this process. This phenomenon begets a buoyancy-driven flow in the liquid PCM. In order to develop a simplified mathematical model for simulating the solidification process, various assumptions were used, including:

- transient and incompressible liquid phase flow;

- negligible water temperature alteration and viscous dissipations;

- no-slip condition for liquid at boundaries;

- insignificant influence of temperature variation on PCM thermal features except liquid density in momentum equation calculated by Boussinesq Equation;

- $\quad$ PCM and fins were at $366 \mathrm{~K}$ as initial condition; and

- negligible thermal resistance for junction of tube and fins and isolated outer surface of the external tube

The governing equations of momentum and heat distribution for liquid PCM are defined by the Navier-Stokes and energy equations [17,34,35]: 


$$
\begin{gathered}
\nabla \cdot v=0 \\
\frac{\partial u}{\partial t}+v \cdot \nabla u=\frac{1}{\rho_{p c m}}\left(-\nabla P+\mu_{p c m} \nabla^{2} u\right)+C u \frac{(1-\lambda)^{2}}{\lambda^{3}+\varepsilon} \\
\frac{\partial u}{\partial t}+v \cdot \nabla u=\frac{1}{\rho_{p c m}}\left(-\nabla P+\mu_{p c m} \nabla^{2} v+(\rho \beta)_{p c m} g\left(T+T_{r e f}\right)\right)+C v \frac{(1-\lambda)^{2}}{\lambda^{3}+\varepsilon} \\
\frac{\partial u}{\partial t}+\frac{\partial(\Delta H)}{\partial t}+\nabla \cdot(v h)=\nabla \cdot\left(\frac{k_{p c m}}{\left(\rho C_{p}\right)_{p c m}} \nabla H\right)
\end{gathered}
$$

where $\mu, P, r$, and $v$ depict dynamic viscosity, pressure, velocity in $\mathrm{r}$ direction and velocity in $\theta$ direction, respectively. Once the PCM becomes solid and velocity reaches zero, the constant of mushy zone $(C)$ become the controller of damping given in the above equations. Mushy zone constant is generally in the range of $10^{5}-10^{6}$ [36]. In this research, the value of $10^{5}$ was more suitable to validate the real outcomes [33]. $h$ and $\Delta H$ are sensible enthalpy and latent heat, respectively. Furthermore, $\epsilon$ was adjusted to a tiny number (0.001) in order to prevent the division by zero. Sensible enthalpy is formulated as:

$$
h=h_{r e f}+\int_{\mathrm{T}_{r e f}}^{\mathrm{T}} C_{p} d T,
$$

where $T_{r e f}, h_{r e f}$, and $C_{p}$ illustrate the reference temperature equal to $273 \mathrm{~K}$, reference enthalpy at reference temperature, and specific heat at constant pressure. Latent heat is calculated by:

$$
\Delta H=\lambda \Gamma .
$$

In Equation (6), $\Gamma$ refers to latent heat of fusion $(J / \mathrm{kg} \mathrm{K})$ and $\lambda$ is a parameter that can alter from zero (showing the solid state) to 1 , which demonstrates the liquid phase. Indeed, it shows remaining liquid fraction when temperature is between $T_{s}$ and $T_{l}$. It is expressed as follows:

$$
\lambda=\left\{\begin{array}{c}
0 T \leq T_{s} \\
\frac{T-T_{s}}{T_{l}-T_{s}} T_{s}<T<T_{l} . \\
1 T \geq T_{l}
\end{array}\right.
$$

The Equation (8) gives the energy balance of fins:

$$
\frac{\partial\left(\rho_{C u} C_{P . C u} T_{C u}\right)}{\partial t}=\nabla \cdot\left(k_{C u} \nabla T_{C u}\right),
$$

where $\rho, C_{p}$, and $k$ show density, specific heat, and thermal conductivity of the fins respectively while subscript of $\mathrm{Cu}$ is to indicate that copper fins were used in this study.

\subsection{Fin Details}

Rectangular fins used in this research had fin length in direction of the triplex-tube annulus of $l$, fin length in cross section of the annulus $(L)$ and width of $(w)$. Therefore, the volume occupied by fins $\left(V_{f}\right)$ and volume fraction $\left(\phi_{f}\right)$ of fins in this system can be calculated by the following equations:

$$
\begin{gathered}
V_{f}=N \times(L \times w) \times l, \\
\varphi_{f}=\frac{V_{f}}{V_{t}},
\end{gathered}
$$




$$
w=\frac{\pi\left(r_{o}^{2}-r_{i}^{2}\right)}{N \times b} \varphi_{f} .
$$

In above equations, $N$ and $V_{t}$ are the number of fins and the total volume of the TES system. The $\phi_{f}$ was estimated based on different fin dimensions utilized in this study. This value for the fins with lengths of $42 \mathrm{~mm}, 28 \mathrm{~mm}$, and $18 \mathrm{~mm}$ and widths of $1 \mathrm{~mm}, 1.5 \mathrm{~mm}$, and $1 \mathrm{~mm}$ is approximately equal to $0.0215,0.0215,0.0143$ and 0.0092 , respectively that illustrate the space filled with fins in the PCM area.

\subsection{Mesh Independency}

In this numerical model, partial differential equations (Equations (1)-(5) are solved using CFD code-ANSYS FLUENT 2019-R1). In order to simulate the solidification of molten PCM, the Pressure-based method was applied due to its suitability for incompressible flows, while the momentum and energy equations (Equations (1)-(5)) were solved after discretization by the finite volume method with the Second Order Upwind scheme. Furthermore, SIMPLE algorithm was adopted for the pressure-velocity coupling in the momentum equations (Equations (2) and (3)) besides the Second Order scheme for pressure correction. The solidification of the PCM was modeled by the enthalpy-porosity method. In this technique, the area contains both phases together (Mushy zone) was assumed as a 'pseudo' porous media possessing the porosity equals to the liquid fraction. For solidification, the porosity scores from 1 that demonstrates the liquid phase to amount of 0 , which is the symbol of the solid phase. Actually, the melt interface tracking is replaced by a special liquid fraction dedicated to every computational cell $[17,28]$.

On the other hand, to run the numerical model, a $20 \mathrm{~s}$ time interval was chosen for iterations that could maintain the model stability during the simulation of all case studies. Moreover, the under-relaxation factors were assumed to be $0.5,0.3,0.3$, and 0.8 for velocity components, liquid fraction, pressure correction, and energy equations, respectively.

In addition, to ensure the independency of the acquired outcomes from the element size and mesh topology, a mesh independency investigation was conducted by comparing the average temperature of whole PCM area for five grid arrangements with specific element sizes of $0.25,0.5,1.0,1.5$, and $2.0 \mathrm{~mm}$ and the total number of cells $=365,600,94,940,24,072,10,920$, and 6136 respectively. The results obtained from the mesh independency study showed that the element size of $0.5 \mathrm{~mm}$ was reliable, whereas by using smaller size of cells almost similar results were obtained that did not justify using them, i.e., considering the significant increase in the computational time with higher number of elements. The outcomes of this mesh independency study are presented in Figure 2. 


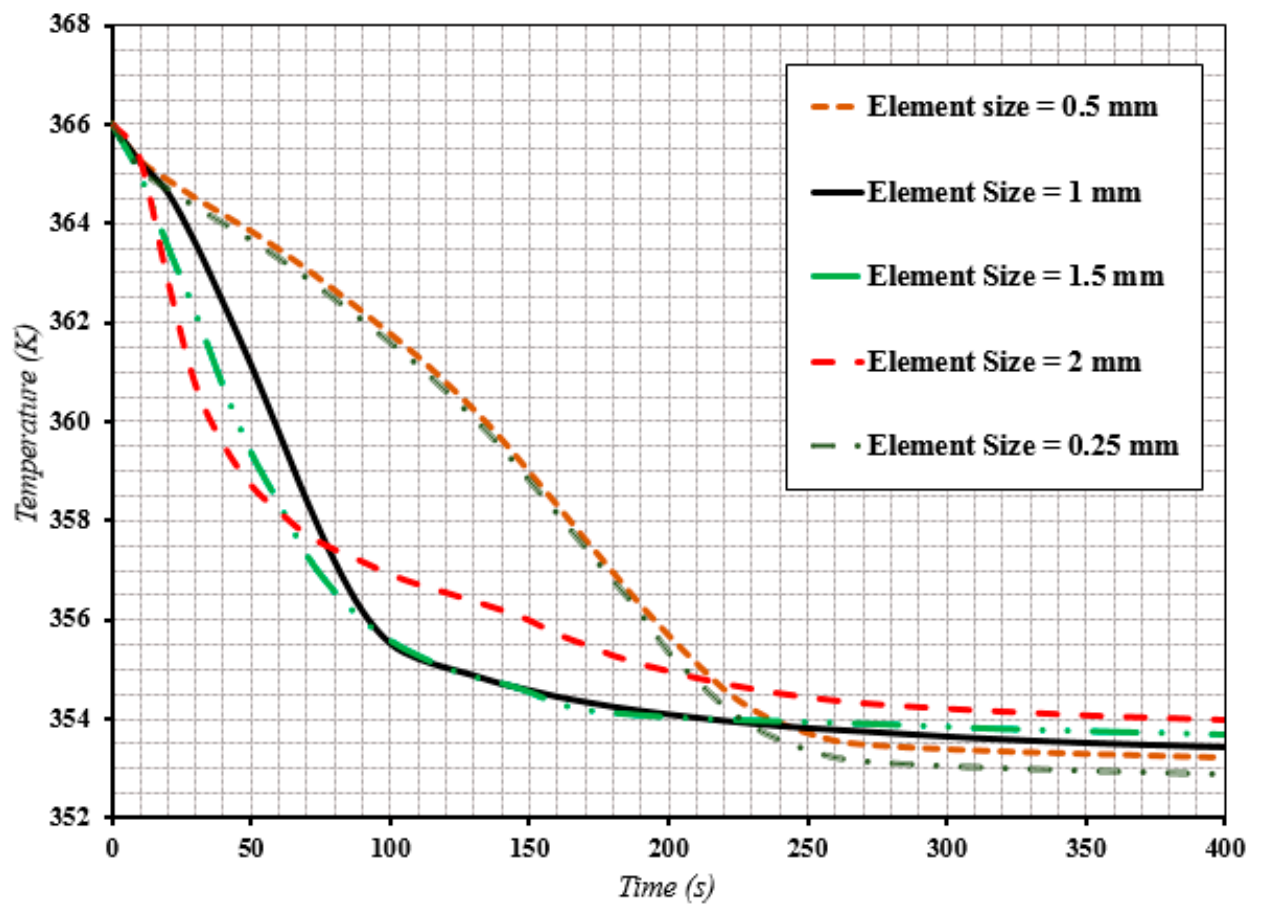

Figure 2. The mesh independency investigation.

\subsection{Model Validation and Precision Assessment}

In order to validate the results of the simulation study, they were compared with the experimental values reported by Al-Abidi et al. [33]. The thermo-physical properties of RT82 PCM were used in our numerical study, similar to that used in the study conducted by Al-Abidi et al. [33]. The details of these properties used in the model are provided in Table $1[17,33]$.

Table 1. Thermo-physical properties of phase change material (PCM), enhanced with fins, and nanoparticles $[17,33]$.

\begin{tabular}{cc}
\hline Property & PCM (RT82) \\
\hline Density, Liquid $\left(\mathrm{kg} / \mathrm{m}^{3}\right)$ & 770 \\
Specific Heat $(\mathrm{J} / \mathrm{kg} \mathrm{K})$ & 2000 \\
Thermal Conductivity $(\mathrm{W} / \mathrm{m} \mathrm{K})$ & 0.2 \\
Thermal Expansion Coefficient $\left(\mathrm{K}^{-1}\right)$ & 0.001 \\
Latent Heat of Fusion $(\mathrm{J} / \mathrm{kg})$ & 176,000 \\
Dynamic Viscosity $(\mathrm{kg} / \mathrm{m} \mathrm{s})$ & 0.03499 \\
Melting Temperature $(\mathrm{K})$ & $351.15-355.15$ \\
\hline
\end{tabular}

Figure 3 demonstrate the average temperature variation of the PCM area during solidification from the starting point up to the time of $2100 \mathrm{~s}$ with a $300 \mathrm{~s}$ time interval based on the existing experimental results reported in the literature. The mean absolute percentage error (MAPE) and mean absolute deviation (MAD) were also calculated to be $0.532709 \%$ and 1.866905 , respectively. Then they were compared with the experimental values extracted from Al-Abidi et al. [33] study. This comparison (i.e., Figure 3) suggests a strong agreement between the experimental data and the CFD results. Maximum deviation of the CFD results from the experimental data occur towards the end of the $2100 \mathrm{~s}$ period chosen for the simulation, that was only just over $1 \%$. This close agreement confirms the reliability of our CFD simulation for further investigation of the case to optimize the fins design. 


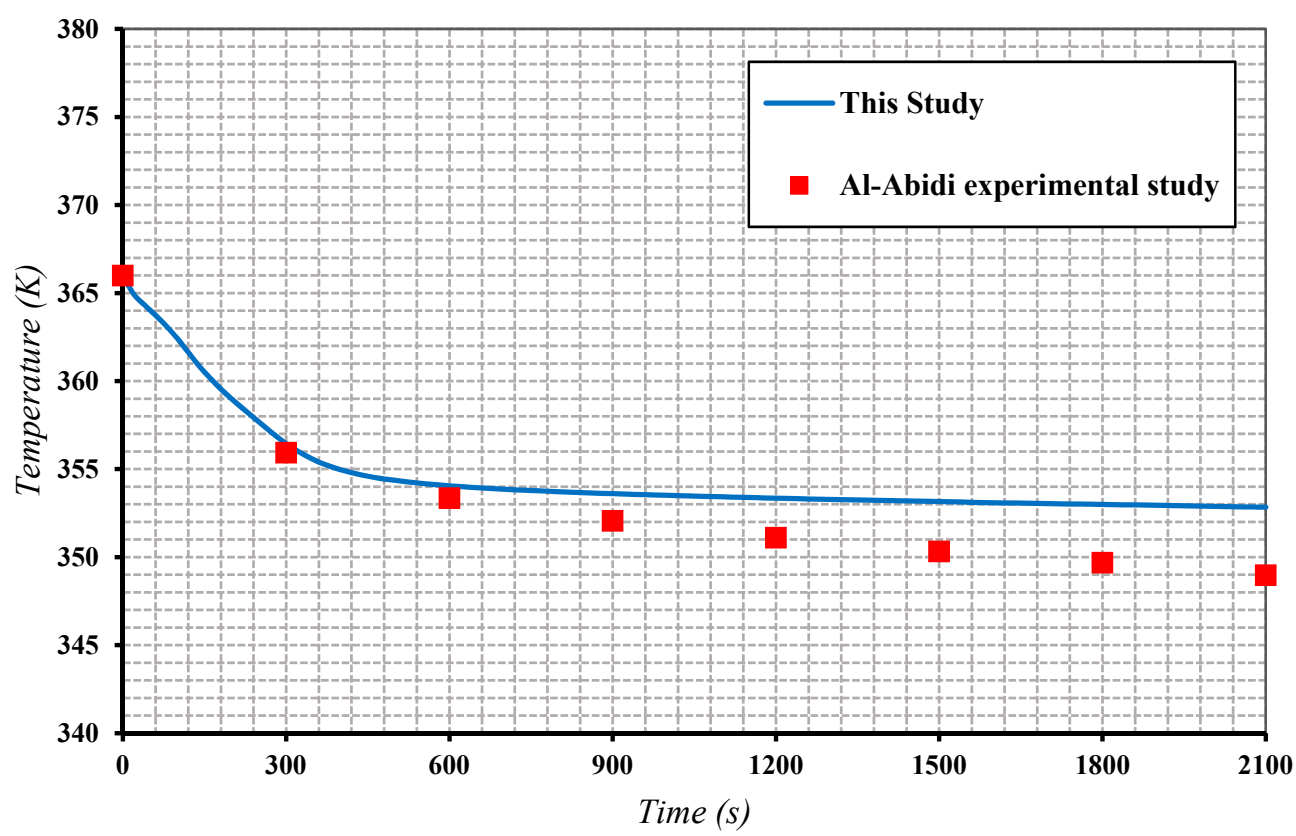

Figure 3. Comparison of the temperatures obtained from the CFD simulation (this study) with the experimentally values reported by Al-Abidi et al. [33].

\section{Results and Discussion}

Generally, different effective parameters were considered in the present study to investigate the effect of using copper fins for solidification enhancement of the PCM. The effect of the fins' presence was studied by benchmarking the performance of the TES system with fins with a base scenario in which no fins were applied. As stipulated before, key parameters such as fins' dimensions (length and width), fins' configuration (on the surface of internal tube, external tube or mix method), and the fins' angle of attachment (i.e., for two angles of $45^{\circ}$ and $90^{\circ}$ ) were specifically studied. This was done in order to understand the most effective design specifications for the fins and hence the best operating condition for the TES system. Table 2 presents all details of different case studies.

Table 2. The details of all case studies.

\begin{tabular}{cccccc}
\hline No. & Case Study & Fins Position & Length $(\mathbf{m m})$ & Width $(\mathbf{m m})$ & Angle \\
\hline 1 & Without Fin & - & - & - & - \\
2 & $45-$ Internal $(1 \times 42)$ & On the internal tube & 42 & 1 & $45^{\circ}$ \\
3 & 45-Mix $(1 \times 42)$ & On both internal and external tubes & 42 & 1 & $45^{\circ}$ \\
4 & 45 -External $(1 \times 42)$ & On the external tube & 42 & 1 & $45^{\circ}$ \\
5 & 90 -Internal $(1 \times 42)$ & On the internal tube & 42 & 1 & $90^{\circ}$ \\
6 & 90 -Mix $(1 \times 42)$ & On both internal and external tubes & 42 & 1 & $90^{\circ}$ \\
7 & 90 -External $(1 \times 42)$ & On the external tube & 42 & 1 & $90^{\circ}$ \\
8 & 90 -Mix $(1 \times 18)$ & On both internal and external tubes & 18 & 1 & $90^{\circ}$ \\
9 & 90 -Mix $(1.5 \times 28)$ & On both internal and external tubes & 28 & 1.5 & $90^{\circ}$ \\
10 & 90 -Mix $(1 \times 28)$ & On both internal and external tubes & 28 & 1 & $90^{\circ}$ \\
\hline
\end{tabular}

Figures 4 and 5, illustrate the temperature and liquid fraction contours respectively for different fin configurations with similar dimensions (width $=1$ and length $=42$ ) during the time from $1000 \mathrm{~s}$ up to $13,000 \mathrm{~s}$ with a $3000 \mathrm{~s}$ time step. This helps identify the case with the shortest solidification period. 
It is noteworthy that although the fins' angle of attachment $\left(45^{\circ}\right.$ and $\left.90^{\circ}\right)$ has influence on how the PCM is solidified, this effect was not found to be significant since the mix method and applying fins only on the surface of the internal tube had the same results. However, placing the fins on the surface of the external tube showed less improvement effect on the solidification of the PCM for the angle of $90^{\circ}$ while the external fins with the angle of $45^{\circ}$ could decrease the function of the TES systems even more compared to the system without any fins. It is because of the fact that the external fins encourage the natural convection and the heat transfer from the top section of the system. Therefore, the fins located on the lower sections of the system do function more effectively to accelerate the solidification process. This is while for two other cases, all fins play approximately the same role in enhancing the solidification in the presence of natural convection.

Overall, the solidification enhancement can be attributed to the heat conduction through the copper fins that accelerates the heat transfer rate resulting in faster solidification. During the start of the solidification process, natural convection (happening in the PCM area) plays a major role. Afterwards, when the PCM is partially solidified, the main mechanism of heat transfer is conduction through the fins, tubes, and the solidified PCM layers that control the solidification process. Furthermore, using $45^{\circ}$ angle of attachment for the fins offers a slight positive effect compared to the system without fins due to introducing an additional resistance for direct heat transfer from the PCM to the tubes. This hard layer between the surfaces of the tubes and the liquid PCM can suppress the perfect heat transfer and thermal difference, which are required for achieving a better natural convection.

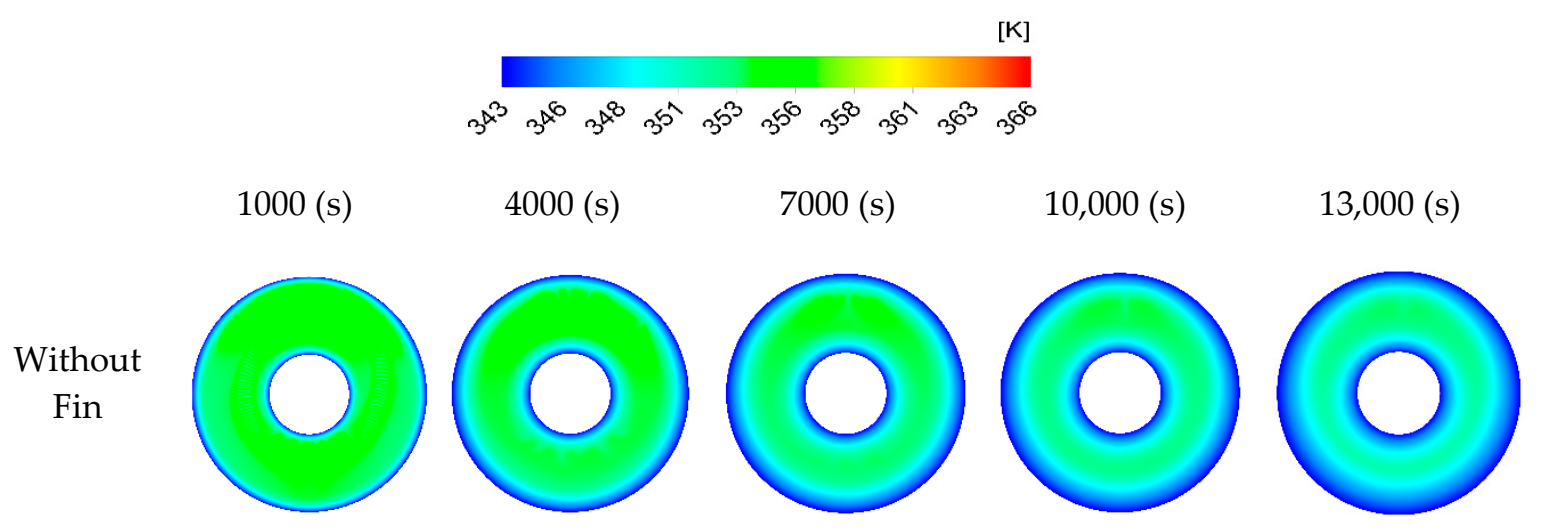

Figure 4. Cont. 
$45-$

Internal
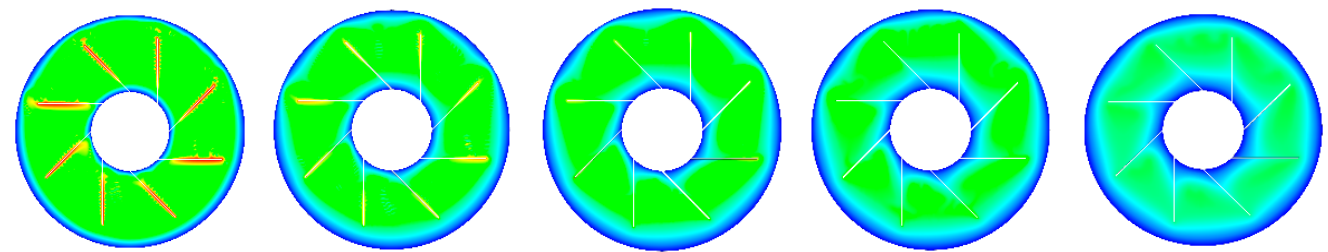

$45-$

External
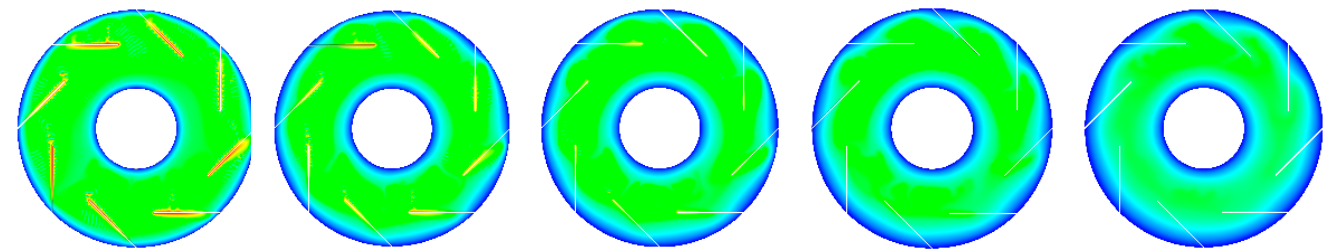

45-Mix
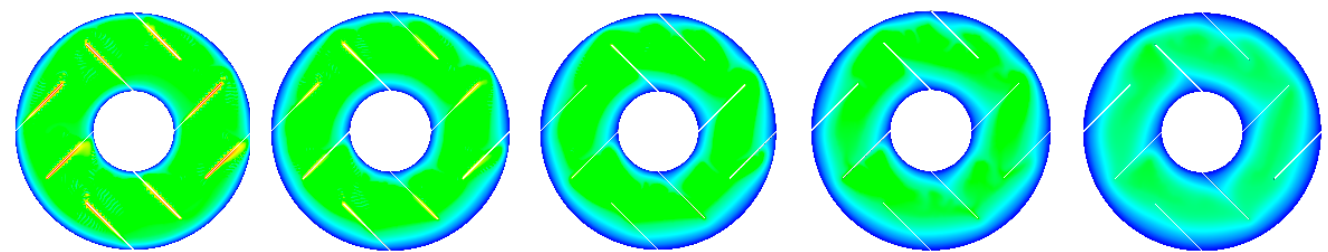

90-
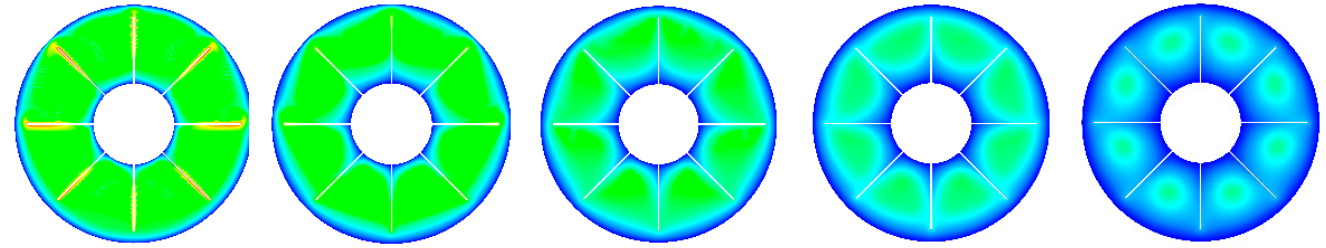

90-

External
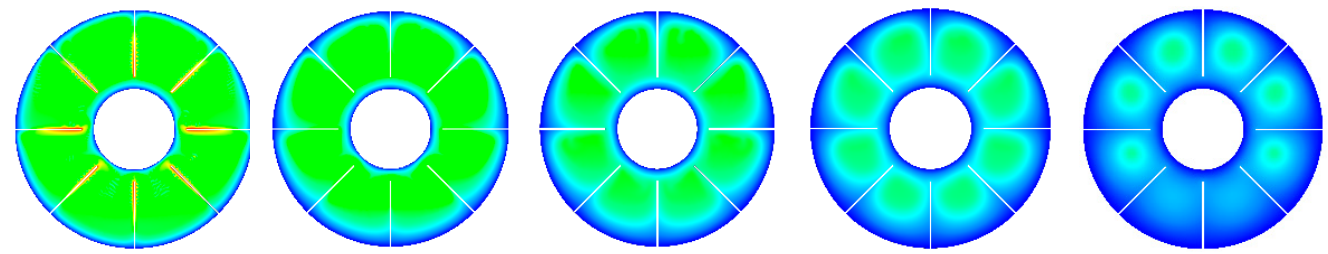

90-Mix
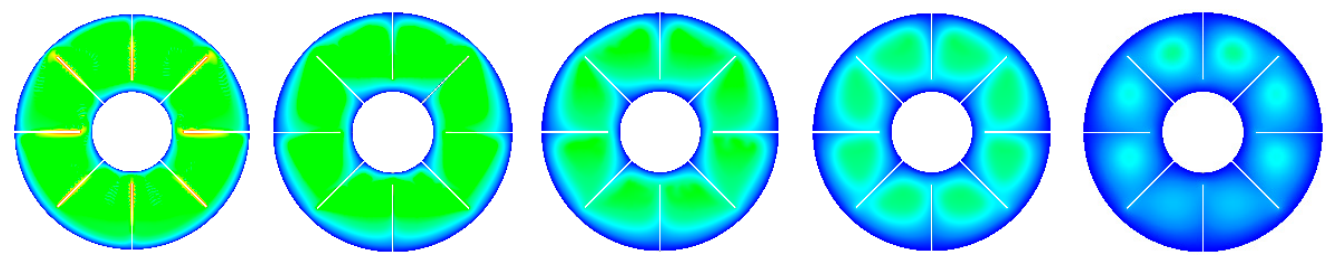

Figure 4. The temperature contours for PCM area with different fins configurations with the same dimensions $(1 \mathrm{~mm} \times 42 \mathrm{~mm})$.

Figure 5 illustrates the liquid fraction contour for different case studies with various fin configurations using fins with similar dimensions. The PCM solidification enhancement can be compared by referring to the time required for solidification. The area of the molten PCM becomes smaller up to the point that the PCM solidifies completely. Overall, at the first stages of the solidification process, the liquid PCM is in direct contact with the cold surfaces of the internal and external tubes and a thin layer of the solidified PCM is formed on the surface of the cold tubes that becomes thicker over time. Thicker solid layer induces a bigger thermal resistance and the solidification abates temporally. 


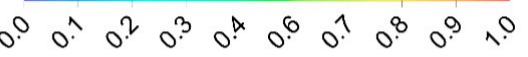
$1000(\mathrm{~s})$
4000 (s)
7000 (s)
10,000 (s)
13,000 (s)
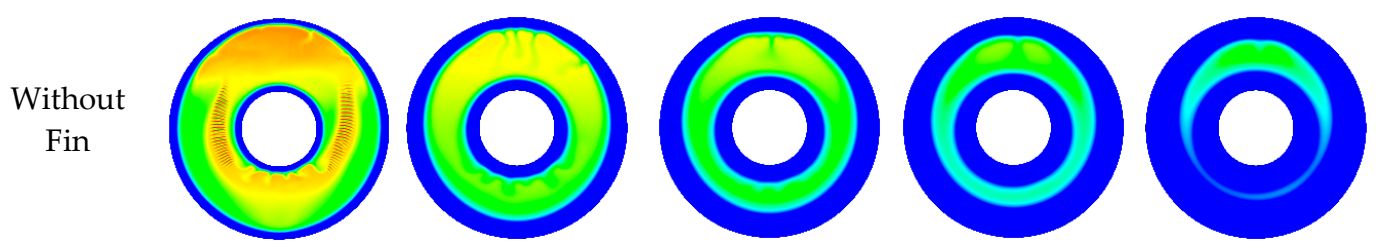

45-

Internal
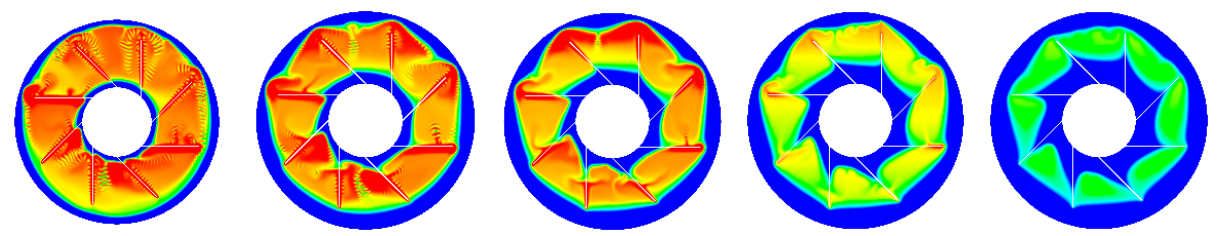

45-
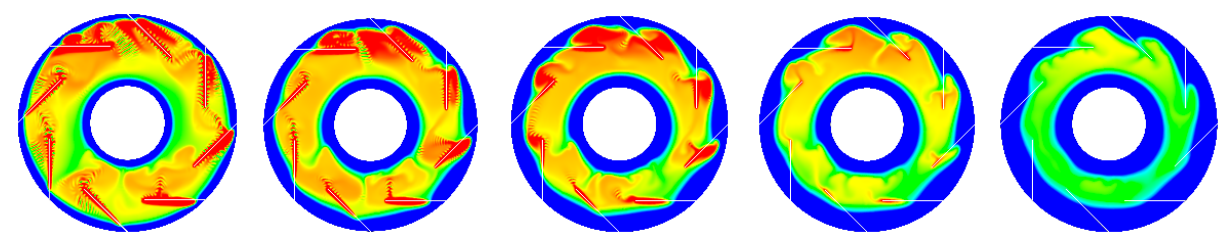

45-Mix
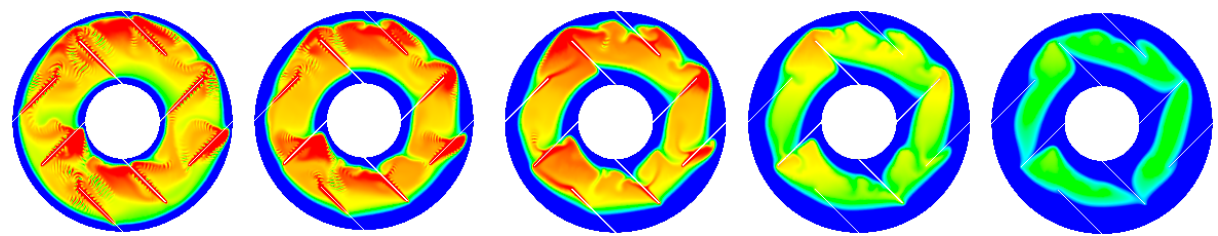

90Internal
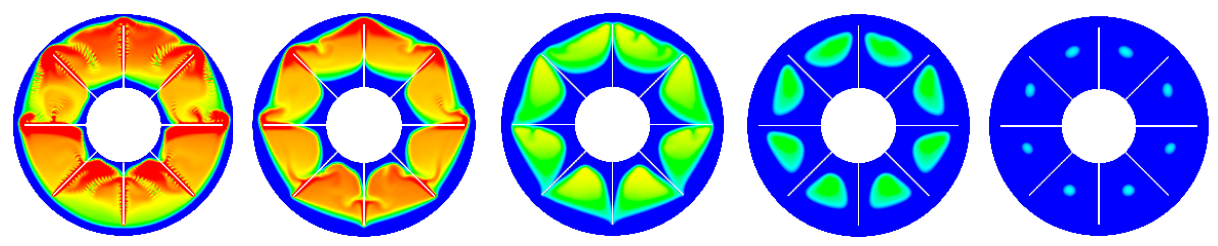

90-

External
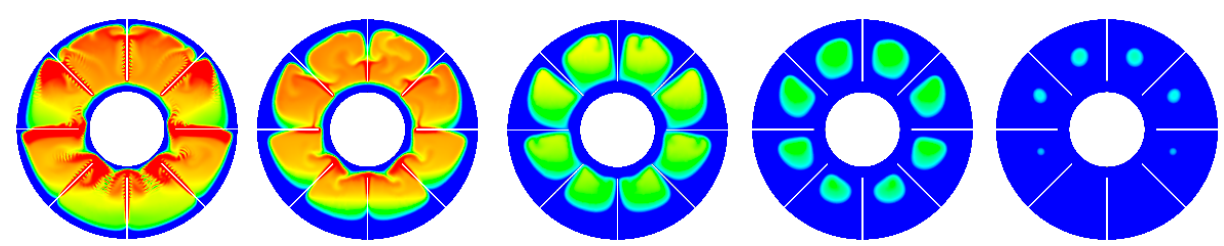

90-Mix
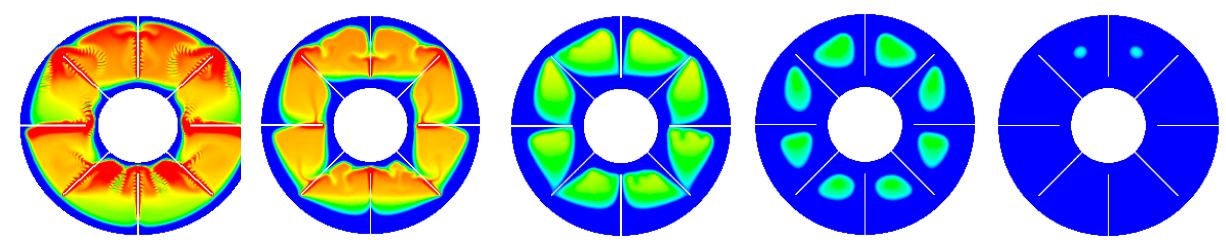

Figure 5. The liquid fraction contours for PCM area with different fins configurations with the same dimensions (1 mm $\times 42 \mathrm{~mm})$. 
In order to investigate the impact of the fins' dimensions on the solidification enhancement, four different dimensions for the system with $90^{\circ}$ fins were considered $(1 \mathrm{~mm} \times 42 \mathrm{~mm}, 1.5 \mathrm{~mm} \times 28 \mathrm{~mm}$, $1 \mathrm{~mm} \times 28 \mathrm{~mm}$, and $1 \mathrm{~mm} \times 18 \mathrm{~mm}$ ). The results (i.e., temperature and liquid fraction contours) were presented in Figures 6 and 7, respectively for 1000-13,000 s with a maximum time interval of $3000 \mathrm{~s}$. It is worth mentioning that the width increase had a negative influence on the performance of the system in terms of solidification enhancement. On the other hand, the length of the fins had a positive effect on reducing the solidification time, since thermal penetration depth is enhanced by using longer fins. Increasing the fins length from $18 \mathrm{~mm}$ to $28 \mathrm{~mm}$ improved the performance of the TES system to a certain level (i.e., $28 \mathrm{~mm}$ ) However, by further increasing this length from $28 \mathrm{~mm}$ to $42 \mathrm{~mm}$, the performance of the system was adversely impacted. It can be concluded that the fin's length has an optimal value to minimize the time required for complete solidification.

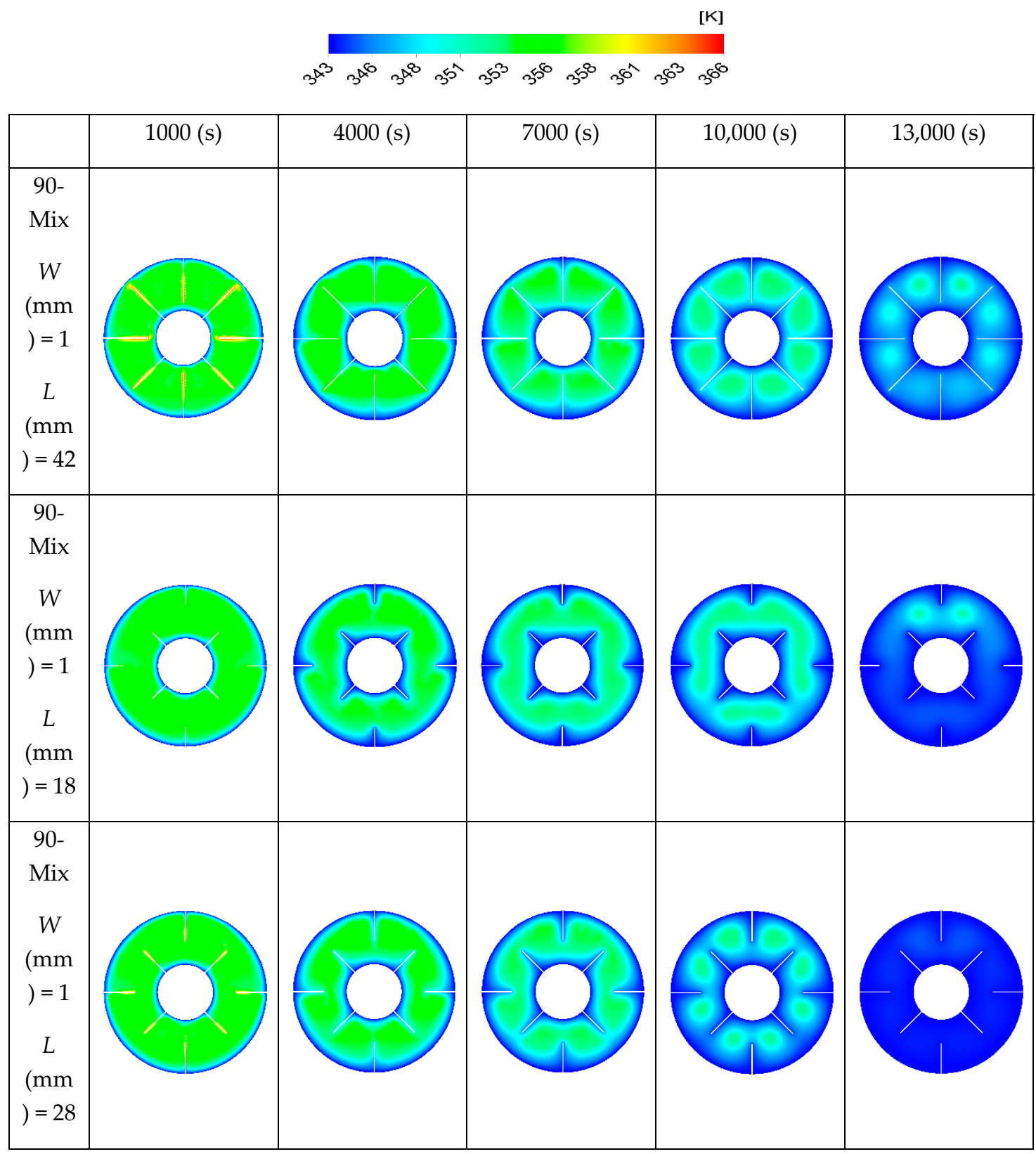

Figure 6. Cont. 


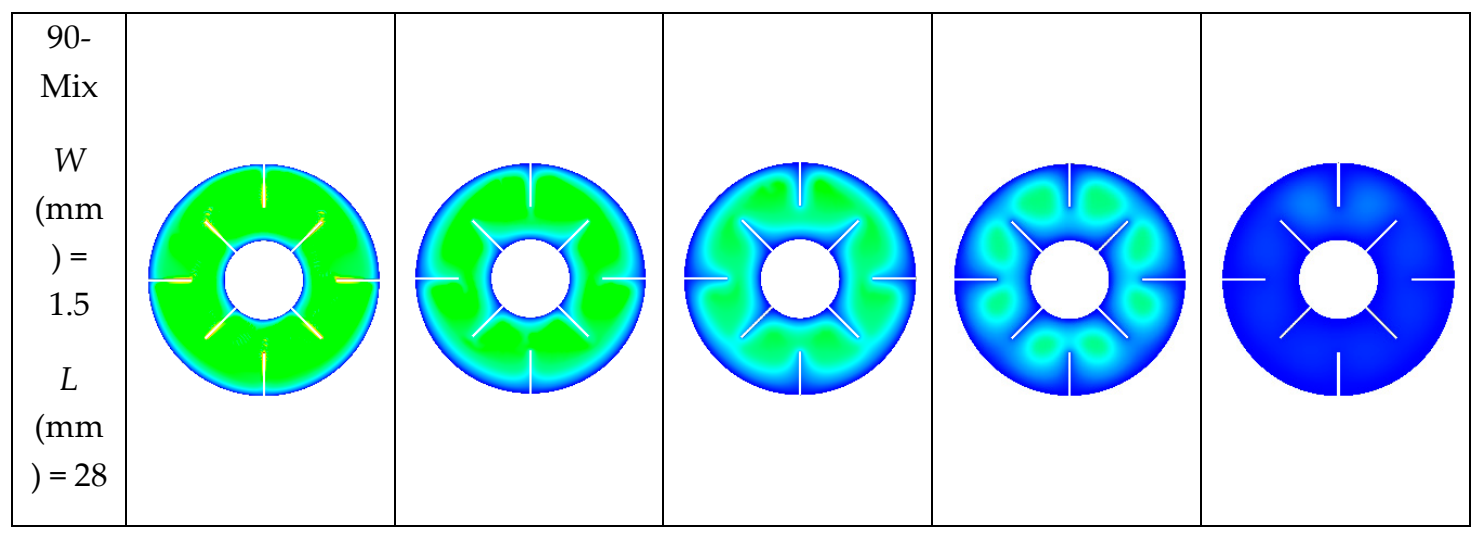

Figure 6. The effect of fins dimensions on the temperature distribution.

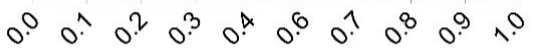

(s)

Figure 7. Cont. 


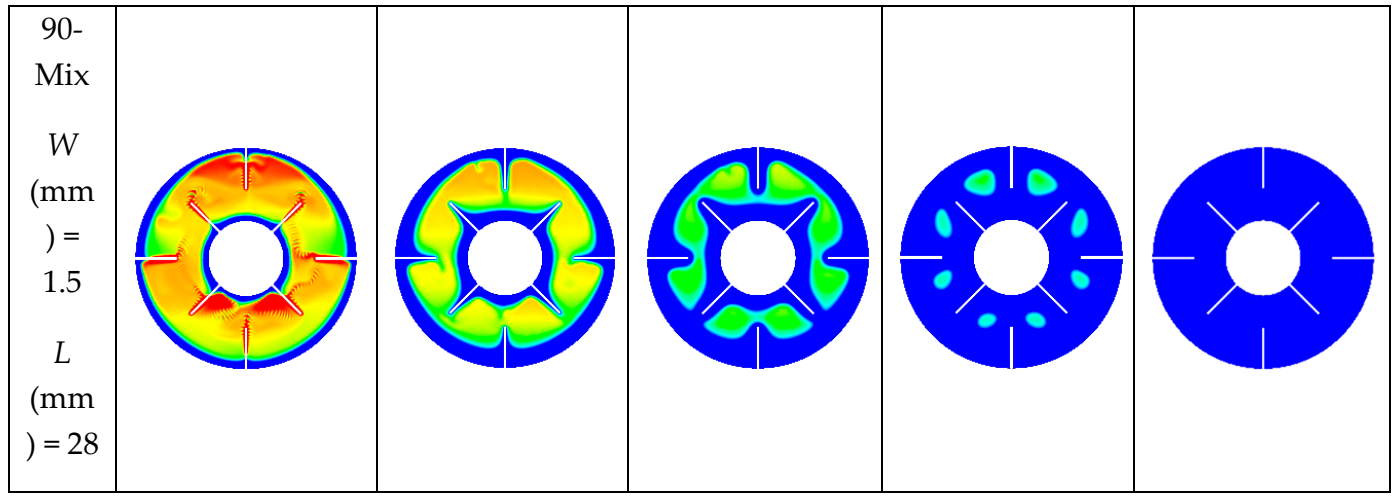

Figure 7. The effect of fins dimensions on the liquid fraction distribution.

The trends of reduction in average temperature and liquid fraction in the area filled with PCM are provided in Figures 8-11. Moreover, in Figures 8 and 9 the time of complete solidification (liquid fraction equals to 0 ) can be seen and compared. The results demonstrate that the complete solidification achieved easier using fins with the width of $1 \mathrm{~mm}$ and length of $28 \mathrm{~mm}$. Furthermore, the angle of $90^{\circ}$ was found to be more effective for attachment of metallic fins. Moreover, fins on both internal and external tubes of the TES system was more beneficial compared to the cases with fins on just one tube. The higher average temperature reveals that the solidification happens later. This is evident by comparing various case studies near the end-point of solidification. The exact required time for complete solidification and the time reduction percentage were given in Table 3 for easier comparison.

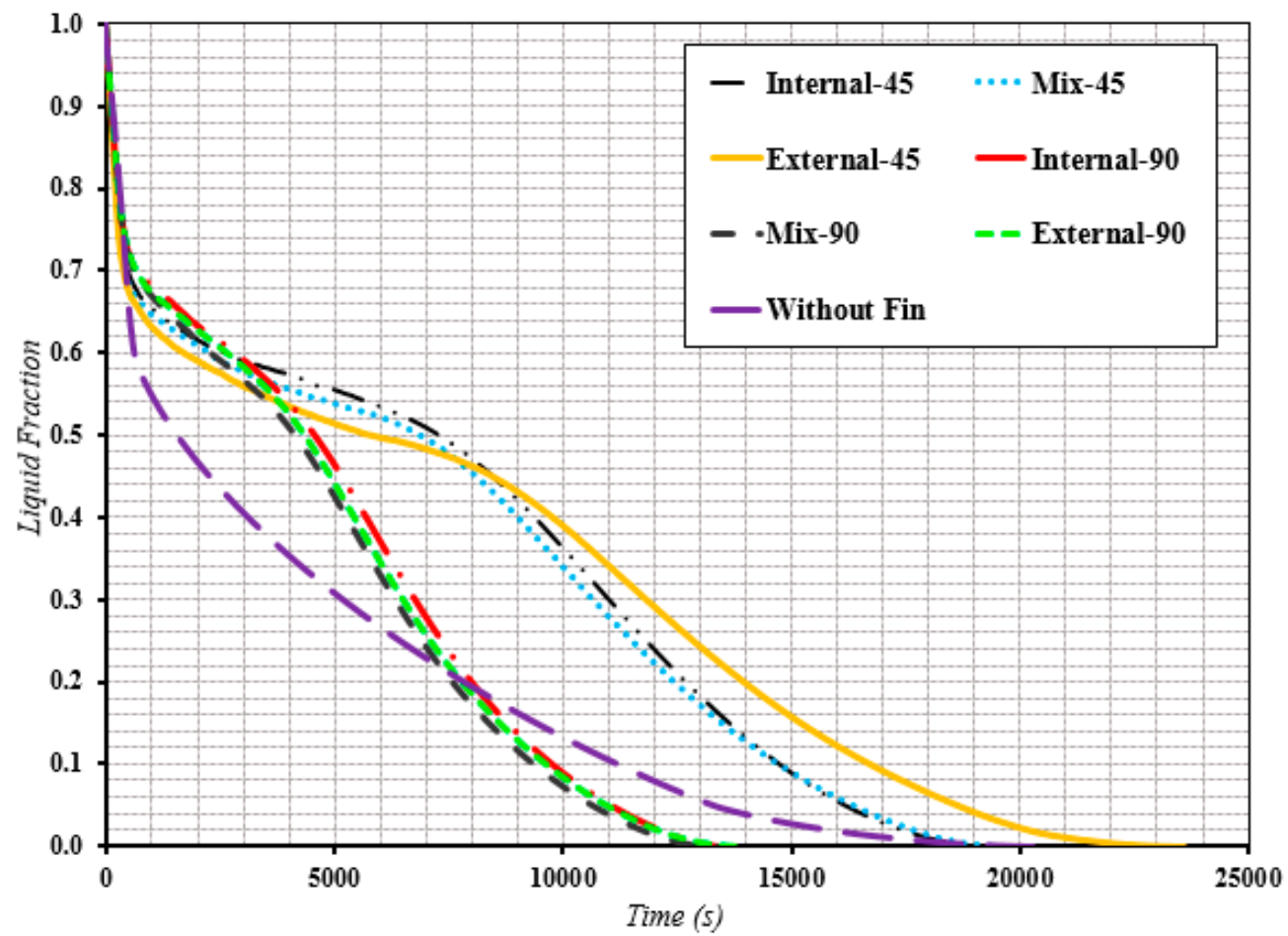

Figure 8. The average liquid fraction of the PCM area with different fins configurations with the same dimensions $(1 \mathrm{~mm} \times 42 \mathrm{~mm})$ during the time. 


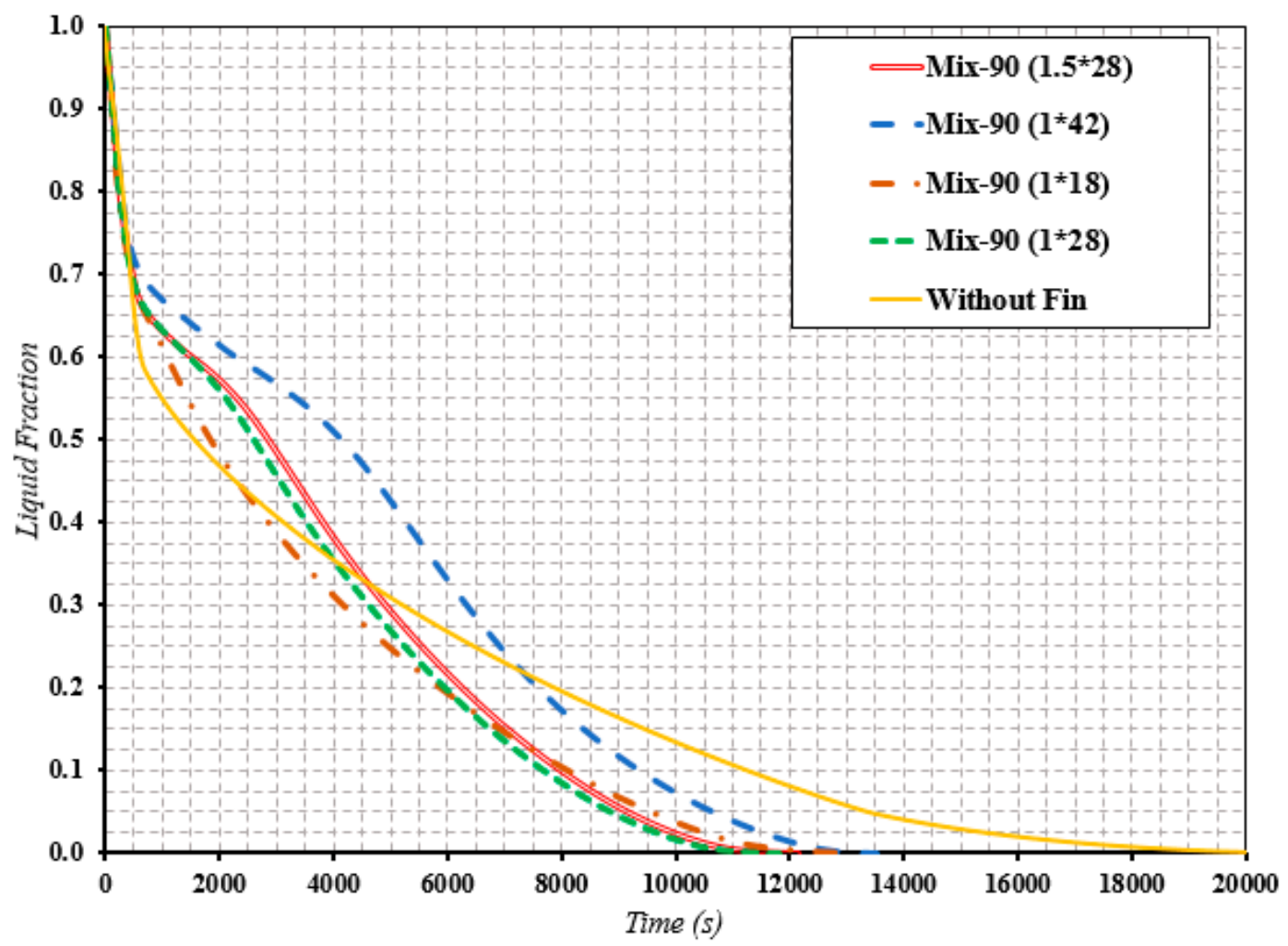

Figure 9. The average liquid fraction during the time for the PCM area with different fins' dimensions.

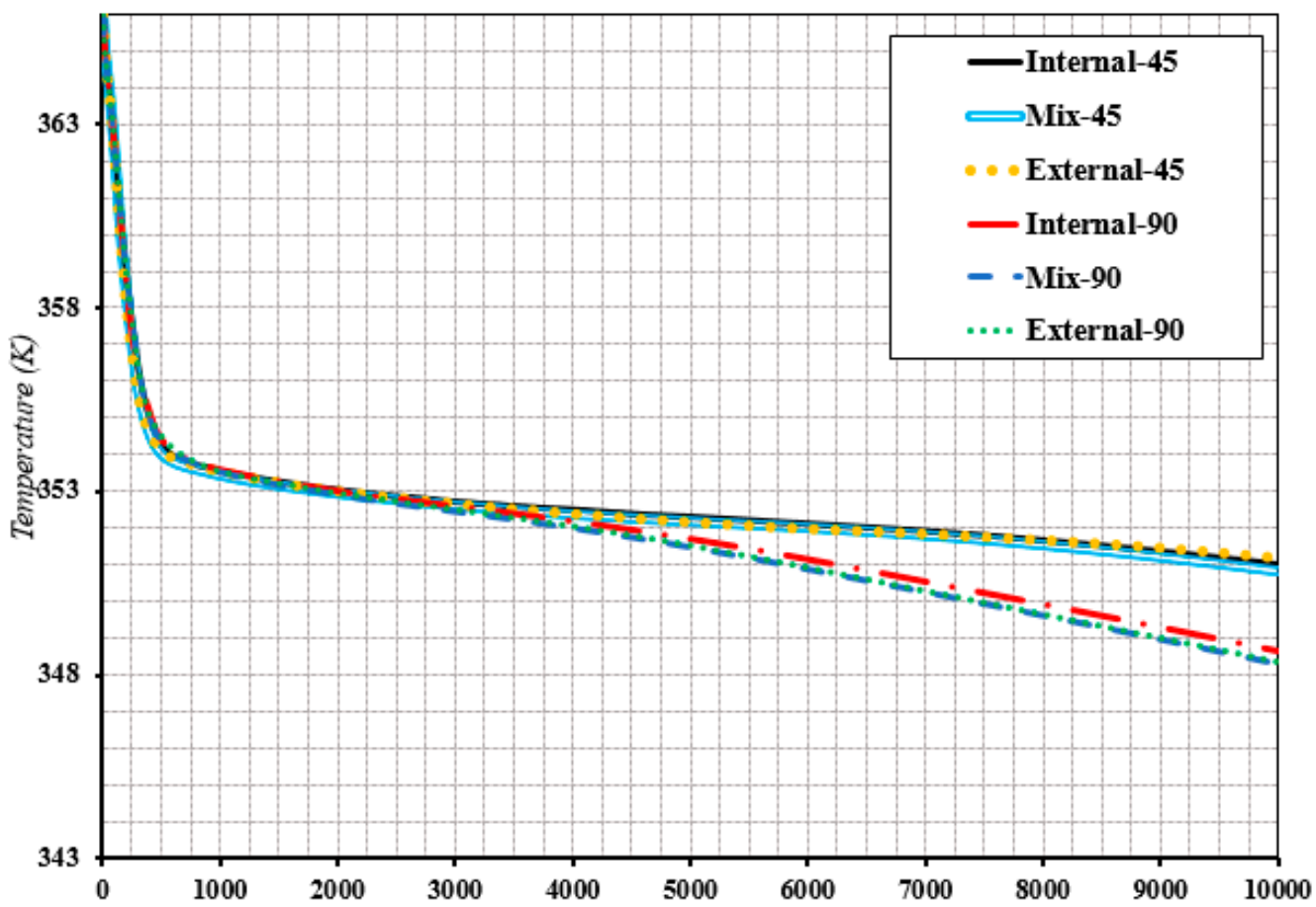

Figure 10. The average temperature of the PCM area with different fins' configurations with the same dimensions $(1 \mathrm{~mm} \times 42 \mathrm{~mm})$ during the time. 


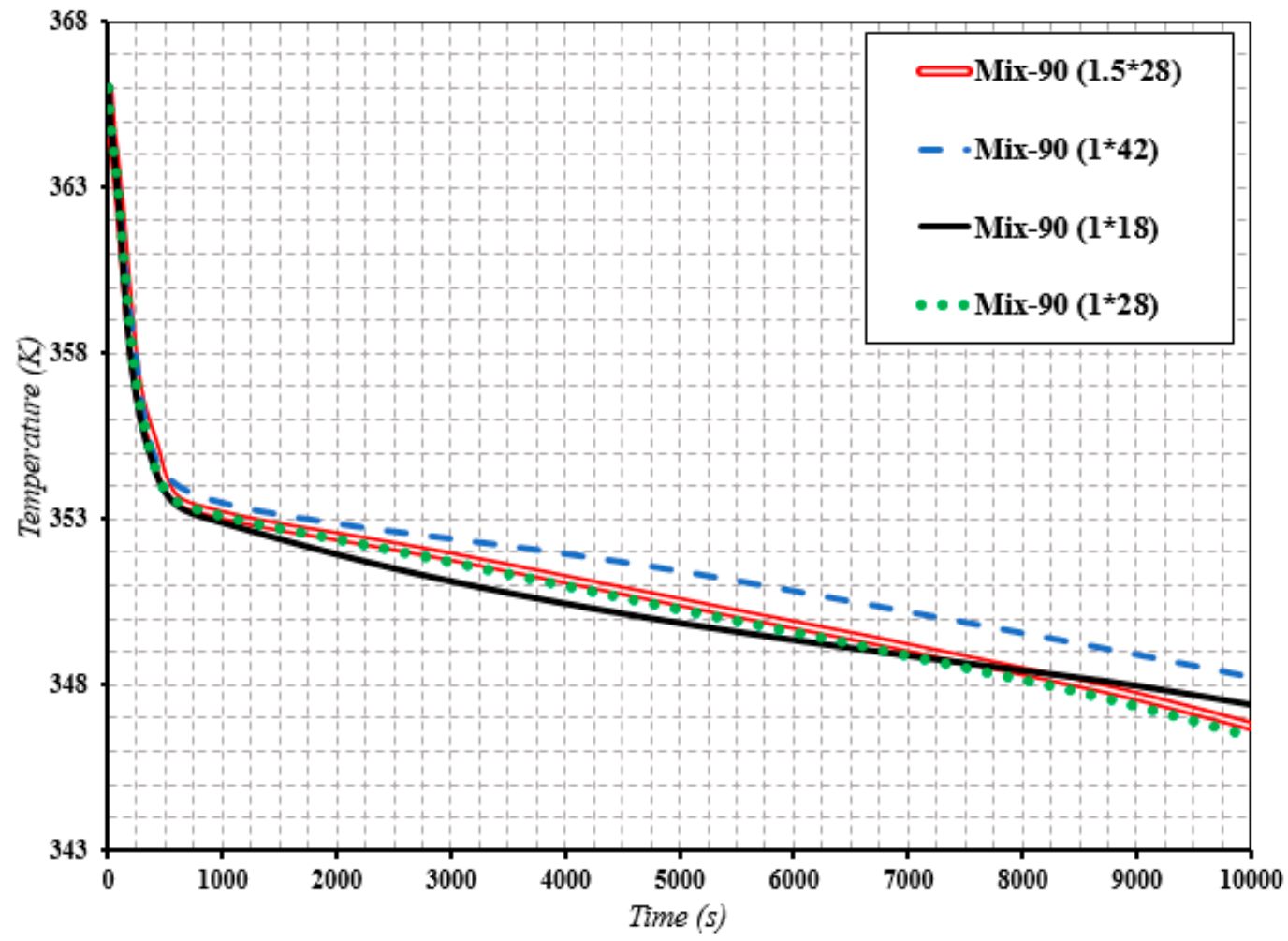

Figure 11. The average temperature during the time for the PCM area with different fins' dimensions.

Table 3 provides the time required for solidification in different cases studied in this research (i.e., without fins and with fins of different design configurations). The table is guiding us through the changes in the time required for solidification in different cases compared to a base case in which no fins were applied. It can be seen that the contact angle of $45^{\circ}$ offered no positive effect on this process but also it adversely affected the performance of the TES system. On the other hand, the best performance was achieved by using the fins with mixed configurations, attachment angle of $90^{\circ}$ and with a length and width of $28 \mathrm{~mm}$ of $1 \mathrm{~mm}$, respectively. This design reduced the required time for complete solidification by about $42 \%$ compared to the system without fins.

Table 3. The required time for the complete solidification and the time reduction percentage for all cases.

\begin{tabular}{ccc}
\hline Case Study & Solidification Time (s) & Time Reduction (\%) \\
\hline Without fin & 20,340 & - \\
45-Internal $(1 \times 42)$ & 19,500 & 4.1 \\
45-Mix $(1 \times 42)$ & 20,000 & 1.7 \\
45-External $(1 \times 42)$ & 23,580 & -15.9 \\
90-Internal $(1 \times 42)$ & 13,540 & 33.4 \\
90-Mix $(1 \times 42)$ & 13,540 & 33.4 \\
90-External $(1 \times 42)$ & 14,020 & 31 \\
90-Mix $(1 \times 18)$ & 13,160 & 35.3 \\
90-Mix $(1.5 \times 28)$ & 12,160 & 40.2 \\
90-Mix $(1 \times 28)$ & 11,800 & 42 \\
\hline
\end{tabular}

\section{Conclusions}

The triplex-tubes are applied as thermal energy storage systems using PCMs that can be used for different applications. In this study, PCM solidification process was modeled numerically and the influences of the presence of rectangular copper fins, their dimensions, configurations, and contact angles on the solidification enhancement were analyzed. The results revealed that the best performance 
belonged to fins with mix configuration, attachment angle of $90^{\circ}$ and with a length of $28 \mathrm{~mm}$ and width of $1 \mathrm{~mm}$, which reduced the required time for complete solidification by $\sim 42 \%$ compared to a similar system without fins. Furthermore, the outcomes of this study showed that there is an optimal value for the length of the fins as thermal performance improves with increasing fin lengths up to this point. In addition, the results demonstrated that changing the fin's configuration did not have a significant impact on the solidification rate although the fins on the surface of external tube had the worst effect. Another effective parameter is the contact angle of the fins attached to the surfaces of the tubes. It was concluded that the function of $90^{\circ}$ angle was remarkably better than the angle of $45^{\circ}$. Fins with the contact angle of $45^{\circ}$ offered no benefit for enhancing the solidification process for both configuration of mix and internal, whereas for the external configuration it could even weaken the performance of the system by up to $15 \%$.

Author Contributions: Conceptualization, M.J.Z. and H.B.; methodology, M.J.Z.; software, M.J.Z., H.B., and M.S.; validation, M.J.Z., H.B., and M.S.; formal analysis, M.J.Z.; investigation, H.B.; reviewing the model and results, B.S. data curation, B.S.; writing - original draft preparation, M.J.Z. and H.B.; writing-review and editing, B.S., M.S., and O.M.; supervision, B.S. All authors have read and agreed to the published version of the manuscript.

Funding: This research received no external funding.

Conflicts of Interest: The authors declare no conflict of interest.

\section{References}

1. Almasoud, A.; Gandayh, H.M. Future of solar energy in Saudi Arabia. J. King Saud Univ. Eng. Sci. 2015, 27, 153-157. [CrossRef]

2. Nematollahi, O.; Hoghooghi, H.; Rasti, M.; Sedaghat, A. Energy demands and renewable energy resources in the Middle East. Renew. Sustain. Energy Rev. 2016, 54, 1172-1181. [CrossRef]

3. Fernandes, D.; Pitié, F.; Cáceres, G.; Baeyens, J. Thermal energy storage: "How previous findings determine current research priorities". Energy 2012, 39, 246-257. [CrossRef]

4. Regin, A.F.; Solanki, S.; Saini, J. Heat transfer characteristics of thermal energy storage system using PCM capsules: a review. Renew. Sustain. Energy Rev. 2008, 12, 2438-2458. [CrossRef]

5. Farid, M.M.; Khudhair, A.M.; Razack, S.A.K.; Al-Hallaj, S. A review on phase change energy storage: materials and applications. Energy Convers. Manag. 2004, 45, 1597-1615. [CrossRef]

6. Agyenim, F.; Hewitt, N.; Eames, P.; Smyth, M. A review of materials, heat transfer and phase change problem formulation for latent heat thermal energy storage systems (LHTESS). Renew. Sustain. Energy Rev. 2010, 14, 615-628. [CrossRef]

7. Zhou, D.; Zhao, C.-Y.; Tian, Y. Review on thermal energy storage with phase change materials (PCMs) in building applications. Appl. Energy 2012, 92, 593-605. [CrossRef]

8. Liu, M.; Saman, W.; Bruno, F. Review on storage materials and thermal performance enhancement techniques for high temperature phase change thermal storage systems. Renew. Sustain. Energy Rev. 2012, 16, $2118-2132$. [CrossRef]

9. Liu, S.; Li, Y.; Zhang, Y. Review on heat transfer mechanisms and characteristics in encapsulated PCMs. Heat Transf. Eng. 2015, 36, 880-901. [CrossRef]

10. Ibrahim, N.I.; Al-Sulaiman, F.A.; Rahman, S.; Yilbas, B.S.; Sahin, A.Z. Heat transfer enhancement of phase change materials for thermal energy storage applications: A critical review. Renew. Sustain. Energy Rev. 2017, 74, 26-50. [CrossRef]

11. Sharma, R.; Ganesan, P.; Tyagi, V.; Metselaar, H.; Sandaran, S. Developments in organic solid-liquid phase change materials and their applications in thermal energy storage. Energy Convers. Manag. 2015, 95, $193-228$. [CrossRef]

12. Real-Fernández, A.; Navarro-Esbrí, J.; Mota-Babiloni, A.; Barragán-Cervera, Á.; Domenech, L.; Sánchez, F.; Maiorino, A.; Aprea, C. Modeling of a PCM TES Tank Used as an Alternative Heat Sink for a Water Chiller. Analysis of Performance and Energy Savings. Energies 2019, 12, 3652. [CrossRef]

13. Hofmann, R.; Dusek, S.; Gruber, S.; Drexler-Schmid, G. Design Optimization of a Hybrid Steam-PCM Thermal Energy Storage for Industrial Applications. Energies 2019, 12, 898. [CrossRef] 
14. Wu, W.; Yang, X.; Zhang, G.; Ke, X.; Wang, Z.; Situ, W.; Li, X.; Zhang, J. An experimental study of thermal management system using copper mesh-enhanced composite phase change materials for power battery pack. Energy 2016, 113, 909-916. [CrossRef]

15. Deng, Z.; Liu, X.; Zhang, C.; Huang, Y.; Chen, Y. Melting behaviors of PCM in porous metal foam characterized by fractal geometry. Int. J. Heat Mass Transf. 2017, 113, 1031-1042. [CrossRef]

16. Esapour, M.; Hamzehnezhad, A.; Darzi, A.A.R.; Jourabian, M. Melting and solidification of PCM embedded in porous metal foam in horizontal multi-tube heat storage system. Energy Convers. Manag. 2018, 171, 398-410. [CrossRef]

17. Mahdi, J.M.; Nsofor, E.C. Solidification enhancement of PCM in a triplex-tube thermal energy storage system with nanoparticles and fins. Appl. Energy 2018, 211, 975-986. [CrossRef]

18. Afridi, M.S.; Anthony, A.; Sundaram, P.; Babu, S. Experimental comparison of longitudinal and annular fins using PCM for Thermal energy storage. IOP Conf. Ser. Mater. Sci. Eng. 2018, 402, 012179. [CrossRef]

19. Parsazadeh, M.; Duan, X. Numerical study on the effects of fins and nanoparticles in a shell and tube phase change thermal energy storage unit. Appl. Energy 2018, 216, 142-156. [CrossRef]

20. Mousavi, S.; Siavashi, M.; Heyhat, M.M. Numerical melting performance analysis of a cylindrical thermal energy storage unit using nano-enhanced PCM and multiple horizontal fins. Numer. Heat Transf. Part A Appl. 2019, 75, 560-577. [CrossRef]

21. Chen, X.; Li, X.; Xia, X.; Sun, C.; Liu, R. Thermal Performance of a PCM-Based Thermal Energy Storage with Metal Foam Enhancement. Energies 2019, 12, 3275. [CrossRef]

22. Singh, R.; Sadeghi, S.; Shabani, B. Thermal conductivity enhancement of phase change materials for low-temperature thermal energy storage applications. Energies 2019, 12, 75. [CrossRef]

23. Henze, R.H.; Humphrey, J.A. Enhanced heat conduction in phase-change thermal energy storage devices. Int. J. Heat Mass Transf. 1981, 24, 459-474. [CrossRef]

24. Lacroix, M. Study of the heat transfer behavior of a latent heat thermal energy storage unit with a finned tube. Int. J. Heat Mass Transf. 1993, 36, 2083-2092. [CrossRef]

25. Velraj, R.; Seeniraj, R.; Hafner, B.; Faber, C.; Schwarzer, K. Experimental analysis and numerical modelling of inward solidification on a finned vertical tube for a latent heat storage unit. Sol. Energy 1997, 60, 281-290. [CrossRef]

26. Gharebaghi, M.; Sezai, I. Enhancement of heat transfer in latent heat storage modules with internal fins. Numer. Heat Transf. Part A Appl. 2007, 53, 749-765. [CrossRef]

27. Sciacovelli, A.; Gagliardi, F.; Verda, V. Maximization of performance of a PCM latent heat storage system with innovative fins. Appl. Energy 2015, 137, 707-715. [CrossRef]

28. Darzi, A.A.R.; Jourabian, M.; Farhadi, M. Melting and solidification of PCM enhanced by radial conductive fins and nanoparticles in cylindrical annulus. Energy Convers. Manag. 2016, 118, 253-263. [CrossRef]

29. Al-Abidi, A.A.; Mat, S.; Sopian, K.; Sulaiman, M.; Mohammad, A.T. Numerical study of PCM solidification in a triplex tube heat exchanger with internal and external fins. Int. J. Heat Mass Transf. 2013, 61, 684-695. [CrossRef]

30. Mahdi, J.M.; Nsofor, E.C. Melting enhancement in triplex-tube latent thermal energy storage system using nanoparticles-fins combination. Int. J. Heat Mass Transf. 2017, 109, 417-427. [CrossRef]

31. Mahdi, J.M.; Lohrasbi, S.; Ganji, D.D.; Nsofor, E.C. Simultaneous energy storage and recovery in the triplex-tube heat exchanger with PCM, copper fins and Al2O3 nanoparticles. Energy Convers. Manag. 2019, 180, 949-961. [CrossRef]

32. Alizadeh, M.; Hosseinzadeh, K.; Ganji, D. Investigating the effects of hybrid nanoparticles on solid-liquid phase change process in a Y-shaped fin-assisted LHTESS by means of FEM. J. Mol. Liq. 2019, 287, 110931. [CrossRef]

33. Al-Abidi, A.A.; Mat, S.; Sopian, K.; Sulaiman, M.; Mohammad, A.T. Experimental study of melting and solidification of PCM in a triplex tube heat exchanger with fins. Energy Build. 2014, 68, 33-41. [CrossRef]

34. Bordbar, A.; Kamali, R.; Taassob, A. Thermal Performance Analysis of Slug Flow in Square Microchannels. Heat Transf. Eng. 2019, 41, 84-100. [CrossRef] 
35. Bordbar, A.; Taassob, A.; Kamali, R. Diffusion and convection mixing of non-Newtonian liquids in an optimized micromixer. Can. J. Chem. Eng. 2018, 96, 1829-1836. [CrossRef]

36. Shmueli, H.; Ziskind, G.; Letan, R. Melting in a vertical cylindrical tube: Numerical investigation and comparison with experiments. Int. J. Heat Mass Transf. 2010, 53, 4082-4091. [CrossRef] 